\title{
Epistemic Reasons I: Normativity
}

\author{
Forthcoming in Philosophy Compass
}

\section{Introduction}

Distinctions. The theory of reasons is Janus-faced. On the one hand, it examines the nature of the reasons for which people act or form attitudes, which needn't be good; such motivating reasons, as meta-ethicists call them, are not the focus here. On the other hand, it examines the nature of normative reasons, which are considerations that count in favor of acts and attitudes. Normative epistemic reasons - our topic here - are a subset of the normative reasons for doxastic attitudes. Delimiting this subset is no easy task. Pieces of evidence are paradigmatic members, but it is controversial whether all normative epistemic reasons are evidence, as we'll see.

Outside of epistemology, it is common to distinguish between the normative reasons there are ("objective normative reasons") and the normative reasons one has ("subjective normative reasons"). An illustration of this distinction in the practical case is Williams (1981)'s celebrated "petrol and tonic" example. Bernie walks into his favorite bar and orders a gin and tonic. His bartender has gone mad and serves him a glass of petrol and tonic, which we're supposed to imagine is superficially indistinguishable. In a clear sense, the fact that the glass contains petrol is a conclusive reason for Bernie not to drink from it. But given the deceptive appearances, Bernie does not possess a conclusive reason not to drink.

Objective reasons have received surprisingly little attention in epistemology. Perhaps they are neglected because it is unclear how they bear on epistemic justification, the status epistemologists most often associate with reasons. But they might bear on other epistemic statuses, such as knowledge. And as we'll see, if one account of subjective reasons is true, then by investigating these reasons, epistemologists just are investigating a special case of objective reasons. Accordingly, this article takes objective reasons seriously as candidate grounds for epistemic normativity.

Structure. The article is structured around the following questions:

1. Ontology. Are normative epistemic reasons mental states, facts, propositions, or what?

2. Subjective vs. Objective and Possession. How should we understand the subjective/objective distinction among normative epistemic reasons? What is it to "possess" a reason?

3. Relation to Evidence. Are all normative epistemic reasons evidence? If not, in virtue of what does a consideration count as an epistemic reason?

4. Reasons and the Rest of Epistemology. How do normative epistemic reasons relate to other epistemic standings like justification, rationality, and knowledge? Do these standings require reasons? Should they be analyzed in terms of reasons?

The list is not exhaustive, but covers many central questions, which $§ 2-5$ address in order. ${ }^{1}$

\footnotetext{
${ }^{1}$ On other issues I lacked space to discuss here, I recommend my annotated bibliography (2014) as a companion piece. One important issue it covers that isn't covered here is the defeat of reasons, a topic that Pollock (1974) and Pollock and Cruz (1999) seminally illuminated.
} 


\section{The Ontology of Normative Epistemic Reasons}

What sorts of things are normative epistemic reasons? Many epistemologists believe they are mental states. $^{2}$ This view-mentalism - is diametrically opposed to the standard view about normative reasons in meta-ethics. The common meta-ethical view-non-mentalism-holds that normative reasons are either facts or apparent facts, typically but not necessarily about the world.

One could hold the same view in epistemology. ${ }^{3}$ Epistemologists' resistance may owe to the concern that it is unclear how a bare fact about the world could justify one in believing anything, as non-mentalism might seem to suggest. A response is (i) to agree that reasons must be possessed to justify and (ii) to agree that mental states help us to possess (or "provide") these reasons, but (iii) to deny that mental states are the normative epistemic reasons. Williamson (2000: 197) put it well: "Experiences provide evidence; they do not consist of propositions. So much is obvious. But to provide something is not to consist of it."

While this point levels the playing field between mentalists and non-mentalists, it hardly settles the debate. So let's consider the pros and cons of each view, starting with non-mentalism. Some commonly cited pros include:

1. Fit with Ordinary Language. Non-mentalism explains why we ordinarily treat as true claims of the form, "The fact that $\mathrm{p}$ is a reason to have doxastic attitude D towards q".

2. Phenomenology. Non-mentalism fits better with the phenomenology of good reasoning: when engaging in good reasoning, our attention is directed at the relevant facts, which often aren't facts about our mental states.

3. Unity. Because non-mentalism is the standard view in meta-ethics, adopting it in epistemology yields a unified ontology of reasons.

4. The Job Description. Evidence must consist in propositions to do its job-e.g., to be an input to inferences to the best explanation, something that can rule out hypotheses by being inconsistent with them, something on which we can conditionalize, etc. ${ }^{4}$

5. Roles for Objective Reasons. By acknowledging objective reasons, non-mentalists can make reasons do more work in epistemology-e.g., analyze less subjective normative statuses, like correctness and knowledge. ${ }^{5}$

One can imagine a mentalist response to each purported advantage. Mentalists might dismiss (1) as mere ordinary language philosophy, insisting in reply to (5) that we can do the work of "objective reasons" with different, more joint-carving concepts. Similarly, mentalists might chalk (4) up to loose talk: strictly speaking, they might say, it is the fact that we have certain evidence that is the input to abductive arguments, and the content of the evidence that is inconsistent with hypotheses and the input to conditionalization. In reply to (2), mentalists could follow objective consequentialists like Railton (1984) and claim that good reasons are not things to which good reasoners must attend or even necessarily can attend. Finally, mentalists could either insist in response to (3) that a disunified ontology of reasons isn't so bad or pursue a unified mentalist ontology instead.

Is there any reason to prefer mentalism? Most defenses have been negative, suggesting that the costs of non-mentalism are too steep.

\footnotetext{
${ }^{2}$ See Davidson (1986), Huemer (2001), Lyons (2009), Pollock (1974), Pollock and Cruz (1999), and Pryor (2000). Conee and Feldman (2004) might be read as mentalists of this sort, but Conee noted (p.c.) that their core mentalist supervenience thesis is consistent with a non-mentalist ontology of reasons: even if mental duplicates must share the same reasons, perhaps the reasons shared are propositions.

${ }^{3}$ Fantl and McGrath (2009), Littlejohn (2012) and Williamson (2000) do. See Ginsborg (2006) for a compromise between mentalism and non-mentalism.

${ }^{4}$ See Williamson (2000) for this argument.

${ }^{5}$ See Schroeder $(2010,2012,2015 a, 2015 b)$ to learn how objective reasons could do such work.
} 
One argument from Turri (2009) is the Argument from Circularity, ${ }^{6}$ which targets the nonmentalist's treatment of perceptual justification. Suppose I see that $p$ and form the belief that $p$. If the reason that justifies me is a fact, what is it? The obvious candidate, Turri suggests, is the perceived fact that $\mathrm{p}$. But, Turri worries, to form the belief that $\mathrm{p}$ on the basis of the fact that $\mathrm{p}$ is circular. So, he concludes, non-mentalism is false.

Non-mentalists may reply by denying that such basing must be viciously circular. Note that believing that $\mathrm{p}$ on the basis of the fact that $\mathrm{p}$ seems fine in some cases. What, for example, justifies my belief that I'm in pain? Plausibly, the sheer fact that I'm in pain. Even if one does not adopt this model, it is a natural model. It couldn't be if Turri were right.

This example suggests a deeper response. Not all responses to reasons are inferential. When one comes to believe one is in pain upon encountering that fact, one forms the belief in direct, non-inferential response to the fact. One doesn't move in a circle because one's process of belief-formation lacks inferential steps. If a fact can be one's reason in this way rather than via inference, non-mentalists needn't permit moving in a circle.

One might then follow McDowell (1995) in thinking that visual experience can "make manifest" certain facts or apparent facts, which can be non-inferential reasons for our beliefs. Of course, some will deny that we are "open to the facts" in this way. But this isn't a complaint about non-mentalism but rather about direct realism. Unless the view is uncharitably defined, there is no in-principle reason why a non-mentalist cannot see the relevant reasons as facts about one's mental life (see Millar (2014)) or about the public looks of things (see McGrath (forthcoming)).

Another argument from Turri turns on justified agnosticism. He considers a case where Nevil withholds judgment on whether there is unnecessary suffering in the world, believes that God exists only if there is not, and so withholds judgment on whether God exists. What is Nevil's reason for the second instance of withholding? Turri thinks the non-mentalist must say it includes the consideration that there is unnecessary suffering in the world, which makes Nevil look irrational.

But non-mentalists needn't paint this picture. They can say that Nevil's ultimate rationale is that the evidence that there is unnecessary suffering in the world is insufficient. If Nevil is rational, this fact is surely the rationale for his first instance of withholding, and so, indirectly, for the second instance. Perhaps Turri assumes the non-mentalist must still regard the proposition that there is unnecessary suffering in the world as part of Nevil's rationale. But this does not follow from non-mentalism alone, which just says that reasons are (apparent) facts. ${ }^{7}$

Turri might reply: "But mustn't the mentalist say that the contents of the causally active doxastic attitudes are the reasons?" The answer is "No". There is a clear rationale for treating belief and withholding asymmetrically. Just as part of the functional role of belief is to treat its objects as eligible premises for reasoning, so part of the functional role of withholding is to treat its objects and their negations as ineligible premises for reasoning. So it is clear why a non-mentalist would count contents of causally active beliefs as reasons but refuse to count contents of causally active withholdings as reasons. Any satisfactory story about the enabling conditions on a proposition's being a reason will entail this asymmetry. And it is only the conjunction of non-mentalism and a substantive theory about enabling conditions that tells us anything about which contents are reasons.

A third argument from Pollock (1974) is the "Subtraction Argument", which Littlejohn (2012: 93) helpfully summarizes as follows: "[I]f you subtract the subject's belief, the fact or proposition believed could not justify anything. Thus, the reasons that justify belief are the subject's mental states." Littlejohn's response is that this argument ignores the distinction between reasons and enabling conditions: one could hold that mental states enable facts or propositions to be reasons without

\footnotetext{
${ }^{6}$ See Turri (2009: 498); cf. Brueckner (2009).

${ }^{7}$ An anonymous reviewer noted that Turri's point might be better made with credences. It is implausible that reasoning from a credence in $p$ to a credence in $q$ can always be cast as reasoning from $p$ to $q$. It is perhaps less obvious that such reasoning can always be recast as bottoming out in reasoning from propositions about how strongly the evidence supports a conclusion. But I suspect non-mentalists can make that move here. I don't think it's implausible that we ultimately reason to credences from (perhaps implicit) beliefs about epistemic probabilities. While ordinary reasoners don't use the words "epistemic probability", they can surely express thoughts about them in plainer language, just as they can express thoughts about epistemic possibility with 'might'.
} 
themselves being reasons. I agree that the argument wrongly ignores this distinction, but I'd rephrase the alternative and say that being in certain mental states is only necessary for possessing a normative reason.

Some final arguments flow from arguments for mentalism about motivating epistemic reasons, which are discussed at length in this article's sequel. Davidson (1980) famously maintained that rationalizing explanation is a species of causal explanation and hence that motivating reasons must be causes. To get the conclusion that normative reasons are mental states, one needs two assumptions. One is that motivating and normative reasons are the same kind of thing. ${ }^{8}$ A second assumption is that only mental states can be causes. As Littlejohn (2011) notes, one can view facts as causes. So there is no straightforward causal argument for mentalism. Alternatively, one might deny that reasons themselves are causes (see Dancy (2000)) or deny that normative and motivating reasons are the same kind of thing (see Mantel (2015)).

The arguments for mentalism rest, it seems, on oversights. But if we should prefer non-mentalism, which version should we prefer? One version is factualism, which says that normative epistemic reasons are facts. Another is abstractionism, which says that normative epistemic reasons are propositions, including false ones. Unfortunately, there is not just one question to answer, since one could accept factualism about objective normative reasons while accepting abstractionism about subjective normative reasons. We must consider the objective/subjective reason distinction to see which answers are best.

\section{Possession and the Objective/Subjective Distinction}

\subsection{The Factoring Account}

How should we understand the distinction between subjective and objective normative reasons? There are two kinds of answers. According to the Factoring Account (FA), subjective reasons are a special case of objective reasons: namely, the ones we possess. Schroeder (2008) rejects FA and advocates a dualist view on which there are two fundamental reason-for relations, subjective and objective.

The debate intersects with the ontology debate. Schroeder rejects FA partly because objective normative reasons are facts but (or so he maintains) subjective normative reasons needn't be. He uses Williams's "petrol and tonic" case to support this claim. The subjective reason Bernie has to drink from the glass is the apparent fact that the glass contains gin and tonic. Lord (2010) responds that there are facts to which a defender of FA could appeal, like the fact that the drink has a certain appearance. But there are worries about how Lord's response extends to more extreme cases. If Bernie were radically hallucinating due to a demon, he could still rationally intend to drink. Assuming FA, he must base the intention on an objective reason. The only candidates are facts about Bernie's mental life. Yet it does not seem that Bernie's reason is any such fact. ${ }^{9}$

A second worry about Lord's tack brings us back to epistemology. Not every fact is an objective reason to believe that $\mathrm{p}$. Only facts that bear a certain relation to beliefs are objective reasons. One might think this relation involves an objective connection to truth. After all, reliable indicators are the clearest examples of objective epistemic reasons, and they have an objective probabilistic connection to truth. But this connection is broken in the demon world. So even if defenders of FA can point to facts that could justify our beliefs, these facts may fail to be objective epistemic reasons.

\subsection{An Irenic Proposal and Some Questions}

The debate over FA may rest on a mistake. Perhaps there are important notions that the warring parties are both latching onto, with distinct theoretical roles.

One important notion is tied to rationality. Rationality is an overall property determined by the balance of certain considerations. If it is also an internalist property, the relevant considerations aren't necessarily objective reasons. Perhaps opponents of FA are latching onto the things that play this role, which might be called rationalizers. Rationalizers are, I elsewhere argue, apparent facts that subjects

\footnotetext{
${ }^{8}$ Ironically, the classic defender of this claim is Dancy (2000), who uses it to defend non-mentalism.

${ }^{9}$ For responses to this worry, see Lord (2013).
} 
competently treat like objective reasons. ${ }^{10}$ They needn't be objective reasons, since reasons-sensitive competences are fallible and entail reliability only relative to favorable conditions.

It is better if the considerations we treat like objective reasons are objective reasons. We want justifications, not mere excuses. ${ }^{11}$ Perhaps proponents of FA are latching onto the considerationsjustifiers - that satisfy this desire. Justifiers are, I argue elsewhere, facts we can correctly treat as objective reasons as a manifestation of our reasons-sensitive competence. ${ }^{12}$ Extending Sosa (2007)'s language, justifiers are facts we can aptly treat as objective reasons. Since apt treating entails competent treating, all justifiers are rationalizers. But not all rationalizers are justifiers, since competent treating doesn't entail apt treating. Even if one dislikes the terminology, the underlying distinction is clear.

Henceforth I will speak more neutrally of the distinction between subjective reasons and possessed objective reasons. My view multiplies our questions. We now must ask (Q1) what relation one must bear to $\mathrm{p}$ to have $\mathrm{p}$ as a subjective reason, and (Q2) what relation one must bear to an objective reason to possess it. (Q2) breaks down into two sub-questions, because there are two conditions on possession. One is the condition of access to reason-giving facts, which tells us that only facts to which one has access can be reasons one possesses. One sub-question is what such access involves.

Importantly, one can have access to a fact $F$ that is an objective reason to believe that $p$ without possessing that very objective reason. Imagine $\mathrm{F}$ is an objective reason to believe $\mathrm{p}$ because $\mathrm{F}$ entails $\mathrm{p}$ via an arcane deductive route one lacks the logical competence to follow. Plausibly, one doesn't possess $\mathrm{F}$ as an objective reason to believe that $\mathrm{p}$. Hence, there is a second condition on possession I dub sensitivity to the reason-for relation. ${ }^{13}$ A second key question is what such sensitivity involves.

\subsection{Access}

One could try to analyze access in epistemically normative terms - say, in terms of justified belief or, if it is normative, knowledge. But if we do, we may have to abandon hope of analyzing all epistemic normativity in terms of reasons. Possessed reasons, after all, would do most of the work in epistemology. If they must be analyzed via further epistemically normative notions, we cannot understand those in terms of possessed reasons on pain of circularity or regress.

A different approach is to understand access in non-normative terms. There are superficially nonnormative notions to which we could appeal as modes of access - seeing that $\mathrm{p}$, remembering that $\mathrm{p}$, intuiting that $\mathrm{p}$, etc. But whether appealing to them gives us a non-normative grip on access will turn on two further questions - viz., (i) whether all factive mental states are determinates of knowledge and (ii) whether knowledge is normative.

Williamson (2000) gives a positive answer to (i). Many epistemologists believe that knowledge is normative because it entails justification, a paradigmatically normative notion. But we might deny that knowledge is normative even if it entails justification. ${ }^{14}$ Knowledge could entail justification without being constituted by it; compare how pleasantness entails intrinsic goodness on hedonist axiologies. Alternatively, we could deny that all factive mental states are determinates of knowledge.

Since I cannot resolve these issues here, I'll merely note the choice points: if we want to analyze all epistemic normativity in terms of reasons, we face pressure to analyze access in non-normative terms, and if we don't want to analyze all epistemic normativity in terms of reasons, we are free to analyze access in normative terms.

If we turn to subjective normative reasons, it is easier to opt for the first choice. Since subjective reasons can be merely apparent facts, the analogue of the access condition will be non-factive. And there are non-normative, non-factive states to which we can appeal-e.g., seemings.

\footnotetext{
${ }^{10}$ See Sylvan (2015).

${ }^{11}$ For elaboration on this distinction, see Littlejohn (forthcoming) and my (Ms-2). As Littlejohn and I stress, this distinction is common in ethics. In the best work on the distinction in the practical case, it is drawn by appeal to the deeper subjective/objective normative reason distinction; see Gardner (2007).

12 See Sylvan (2015, Ms-2) and Sylvan and Sosa (forthcoming).

${ }^{13}$ One might hold that there are not two conditions on possession but rather one stronger access condition. But I argue against this suggestion below, suggesting that it requires overintellectualization.

${ }^{14}$ For a detailed account along these lines, see my (Ms-1).
} 


\subsection{Sensitivity to Reason-For Relations}

What does it take to be attuned to the reason-for relation between a consideration $r$ and the belief that $\mathrm{p}$ ? Some might say that the subject must be in a position to see that $r$ is a reason to believe $p$. But this is an overintellectualization. To possess reasons, subjects don't need the concept of a reason. Even subjects with the concept needn't deploy it to possess reasons. Some subjects are sufficiently competent that they can cleave to good deductive patterns without representing these patterns in thought, for example. $^{15}$

Now, it is possible to treat a consideration like a normative reason without having or deploying the concept of a normative reason. To treat $r$ like a normative reason of some kind is to be disposed to think in the ways that would be appropriate if $r$ were a normative reason of that kind. Importantly, such treatings can display a familiar trio of properties. A subject's treating a consideration $r$ like a normative reason to believe $\mathrm{p}$ is

- correct, if $\mathrm{r}$ is a normative reason to believe $\mathrm{p}$,

- competent, if the treating manifests a cognitive power to correctly treat $r$-like considerations like reasons to believe p-type propositions, and

- $a p t$, if the correctness of the treating manifests competence.

To possess an objective reason $\mathrm{r}$ of some kind to believe that $\mathrm{p}$, one must aptly treat $\mathrm{p}$ like an objective reason of this kind to believe $\mathrm{p}$. This is the kind of sensitivity possession requires, I suggest.

\subsection{Subjective : Possessed Objective :: Competence : Aptness}

We can understand possessing a good reason $r$ to believe $p$ as involving both access to $r$ and sensitivity to the reason-for relation between $r$ and $p$. The distinction between subjective and possessed objective reasons then owes, I suggest, to a competence/performance distinction with respect to our sensitivity to objective reasons. Note that competences are reliable only relative to favorable conditions. ${ }^{16}$ A skilled golfer retains the competence to sink putts even when unexpected tricksters keep blowing the ball off course. Similarly, one can competently treat considerations like objective reasons even if they wouldn't, if true, be objective reasons, if the appearances are sufficiently misleading.

Hence, subjective reasons can fail to be potential objective reasons. Nevertheless, the capacities that subjects who heed subjective reasons display are the capacities that yield responsiveness to objective reasons in favorable, non-misleading conditions. In such conditions, subjective reasons coincide with possessed objective reasons, and we get justifications, not mere excuses.

\section{Epistemic Reasons and Evidence}

Let's turn to a new question: which normative reasons for doxastic attitudes are epistemic reasons? One answer is:

Strong Evidentialism (SE): All epistemic reasons bearing on whether to believe, disbelieve, or suspend judgment on $\mathrm{p}$ consist in evidence for or against $\mathrm{p}$.

I call SE "Strong” because it is stronger than Conee and Feldman (2004)'s evidentialism, which only claims that epistemic reasons supervene on evidence. The supervenience/grounding distinction aside, a point from Littlejohn shows why SE is stronger. ${ }^{17}$ If one's total evidence for $\mathrm{p}$ is insufficient, one has a conclusive epistemic reason to suspend judgment. This reason is not further evidence for or against p. Hence Strong Evidentialism is false. It doesn't follow, however, that supervenience fails. If the

\footnotetext{
${ }^{15}$ For a further defense of these points, see Sylvan (2015).

${ }^{16}$ For further clarification of the distinction between competences and reliable dispositions, see Sosa (2015).

${ }^{17}$ See this post: http://claytonlittlejohn.blogspot.com/2012/08/evidence-and-epistemic-reasons.html.
} 
sufficiency of a total evidence set is a necessary property of that set, the reason just mentioned supervenes on the evidence and is no counterexample.

Viewing the sufficiency of a total evidence set as a necessary property is controversial. Pragmatic encroachment is one key source of resistance. ${ }^{18}$ While more familiar as a view about knowledge, it is natural enough to extend pragmatic encroachment to the sufficiency of evidence. ${ }^{19}$ One could claim that even if some total evidence is sufficient in one practical environment, it could be insufficient in another with higher stakes (even unbeknownst to one) ${ }^{20}$ This claim conflicts with both SE and the weaker supervenience thesis.

It does not straightforwardly conflict with the following claim:

Weak Evidentialism (WE): Epistemic reasons are (perhaps higher-order) evidence.

Facts about the sufficiency of the evidence are higher-order evidence. While some pragmatic encroachers (e.g., Schroeder (2012)) might maintain that facts about the stakes can be properly epistemic reasons, not all would. Some (e.g., Owens (2000)) would insist that the epistemic reason for withholding in a high-stakes context must be higher-order evidence, not any practical consideration.

WE remains controversial for other reasons. Sometimes opposition to SE rests on appeals to ordinary language. It can be odd to speak of evidence even when there is an epistemic reason. In this vein, Skorupski suggests that epistemic reasons for normative propositions are not evidence, since "[e]vidence involves the notion of... a posteriori inference" (2010: 211). ${ }^{21}$ Notably, the second claim renders all non-inferential epistemic reasons non-evidential, and implies that if traditional foundationalism is true, WE is false. I think such implications recommend a wider use of "evidence". 22

There are other challenges to WE. One emerges from the possibility of requirements that aren't grounded in independent epistemic reasons. Possible examples include wide-scope requirements against incoherent combinations of attitudes. While some are uncertain (see Broome (2013)) or skeptical (see Kolodny (2007))) about whether these requirements generate reasons, others argue that they do (see Reisner (2012)). It would be bizarre to call wide-scope reasons evidence against combinations of mental states, so they may yield counterexamples to WE.

Another challenge is raised by the possibility of epistemic permissions that aren't grounded in prior epistemic reasons. Wright (2004) argues that we have non-evidential epistemic entitlements for hinge propositions. But some (e.g., Jenkins (2007)) doubt that these entitlements are genuinely epistemic.

However these debates are resolved, it is clear that we cannot uncontroversially define "epistemic reasons" in terms of evidence. Is there a more neutral way to explain the difference between epistemic and pragmatic reasons for belief? One suggestion begins with the observation that mere incentives for having intentions, desires, or emotions are just as hard to treat as reasons for these attitudes as incentives for having beliefs are hard to treat as reasons for belief. One would like a general account of why this is so. Some (e.g., Hieronymi $(2005,2013)$ ) pursue this task under the rubric of "right kind" vs. "wrong kind" reason distinction. One possibility, then, is to identify epistemic reasons with right-kind reasons for doxastic attitudes and to leave it up to general meta-normative theory to explain this distinction. ${ }^{23}$

\section{Reasons and the Rest of Epistemology}

What role do normative epistemic reasons play in epistemology? The most ambitious positive answer is given by:

\footnotetext{
${ }^{18}$ Indicator reliabilist views about the quality of evidence like Alston (1988)'s also support resistance, since reliable indicatorship relations are contingent. But opponents of reliabilism will see this feature as a defect.

${ }^{19}$ Indeed an early example of pragmatic encroachment in Owens (2000) and Fantl and McGrath (2002) concerned the sufficiency of evidence.

${ }^{20}$ Schroeder (2012) defends this version of pragmatic encroachment.

${ }^{21}$ Cf. Austin (1962: 115): “[A pig's] coming into view doesn't provide me with evidence that it's a pig, I can just see that it is...."

${ }^{22} \mathrm{Cf}$. Conee and Feldman (2008).

${ }^{23}$ See Skorupski (2010) and Parfit (2011) deny that there are wrong-kind reasons for attitudes, chalking apparent ones up to mere reasons for acts of causing ourselves to have these attitudes. Were they right, we could just identify epistemic reasons with reasons for doxastic attitudes.
} 
Strong Thesis (ST): All epistemic standings (e.g., knowledge, justification, rationality...) are analyzable in terms of reasons.

Friends of ST include Schroeder, Lord, and perhaps defenders of the bolder view that reasons are the sole basic ingredients of normativity. ${ }^{24}$ I say "perhaps" because defenders of the latter view never mention the possibility that some epistemic standings aren't normative. Some epistemologists hold this view about knowledge, ${ }^{25}$ but no reasons-firsters except Schroeder (2015a-b) explicitly take a stand on whether knowledge is normative. Still, given the popularity of normativism about knowledge, most reasons-firsters would probably accept ST.

Because one could hold that some epistemic standings aren't normative, we should distinguish ST from:

Less Strong Thesis (LST): All epistemic normativity is analyzable in terms of reasons. ${ }^{26}$

LST should be distinguished from an even weaker view on which one central kind of epistemic normativity is analyzable in terms of reasons (e.g., the kind associated with deontic notions like permissibility, justification, and obligation), while another is not (e.g., the kind associated with competences). This weaker view is Sylvan and Sosa (forthcoming)'s.

Three kinds of objections to (L)ST are worth distinguishing:

1. Necessity Objections. Reasons are unnecessary for some epistemic standings.

2. Fundamentality Objections. Even if reasons are necessary for all epistemic standings, reasons are not their fundamental normative constituents.

3. Sufficiency Objections. Some epistemic standings cannot be understood just in terms of reasons and non-normative factors.

Reflection on (1-3) will suggest the following upshots. Necessity Objections tend to presuppose mentalism and so aren't conclusive. However, non-mentalist replies to Necessity Objections invite the Fundamentality Objection. The moral I'll suggest is not that we should pursue "reasons eliminationism", ${ }^{27}$ but rather (i) a bi-level epistemology or (ii) non-normativism about some epistemic standings.

\subsection{Necessity Objections}

Lyons (2009) argues against the "Grounds Principle"-i.e., the claim that all beliefs are justified by reasons-as follows:

1. Experiences, if understood as non-doxastic states, cannot be reasons.

2. If (1) is true, then only beliefs can be reasons.

3. But not all beliefs are justified by other beliefs.

4. So, not all beliefs are justified by reasons.

\footnotetext{
${ }^{24}$ Schroeder (2007) upholds the bolder view and has given reasons-based analyses of rationality and knowledge (cf. Schroeder (2008, 2011, 2015b)); Lord (2014) has a similar approach. Other proponents include Parfit (2011), Scanlon (1998), and Skorupski (2010).

${ }^{25}$ Foley $(1987,2004)$ recommends this view. Others (e.g., Goldman (1967), Armstrong (1973), and Dretske (1981)) deny that knowledge is constituted by justification and analyze knowledge via causal or informational relations between beliefs and facts. Kornblith (2008) has reinvigorated this approach. It is natural on such views to deny that knowledge is normative.

${ }^{26}$ Many internalists in epistemology such as BonJour (1986), Conee and Feldman (2004), Huemer (2001), Fumerton (1995), Pollock (1973), and Pollock and Cruz (1999) would embrace this view. Externalists fond of "space of reasons" talk (e.g., McDowell) would also embrace it.

${ }^{27}$ The term is from Kornblith (2015).
} 
In defense of (1), Lyons claims that experiences are either sensations or percepts, in the senses used in psychology. Sensations cannot evidentially ground all justified perceptual beliefs, because it is doubtful that they have representational content. Even if they did, Lyons thinks it would be too low-level to justify most perceptual beliefs. Yet percepts, according to Lyons, cannot be reasons for perceptual beliefs in the key cases, because he thinks they are identical to perceptual beliefs in these cases, occupying all the same functional roles.

One problem with Lyons's argument is that it assumes mentalism. If non-mentalism succeeds, (2) fails. Perceived facts could be grounds of perceptual beliefs. Sure, such reasons cannot justify us unless we possess them. But that doesn't mean the factors in virtue of which we possess reasons are the real reasons. They are simply enabling conditions on the justificatory power of the real reasons.

While this response answers the Necessity Objection, it invites a different objection: reasons aren't doing the fundamental justificatory work anymore. The real work, objectors may claim, is being done by whatever relation a mind must bear to a fact to possess it as a reason. So we face a Fundamentality Objection. Hence, even if the Necessity Objection is answerable, it creates a different objection.

\subsection{Fundamentality Objections}

Accordingly, a deeper worry raised by Necessity Objections is that possession must be understood in distinct normative terms. Another way to see this worry is to consider the following argument against a purely reasons-based analysis of justification:

1. Reasons must be possessed to play a role in the analysis of justification.

2. Possession must be understood in normative terms.

3. So, reasons are not the only normative constituents of justification.

Some go farther and say that because possession must be analyzed in terms of justification, ${ }^{28}$ justification cannot be analyzed in terms of possessed reasons. ${ }^{29}$ But this thought is too quick: there are normative notions distinct from justification to which one could appeal in analyzing possession-e.g., competence.

There are two problems with this argument. Firstly, (3) doesn't follow from (1) and (2). Recall how I appealed to reasons-sensitive competences in analyzing possession. Such competences aren't reasons. But it doesn't follow that we need non-reasons-based ideology to understand justification. The competences are understood in terms of reasons!

A second problem is that (2) is questionable. Most writers on possession have only discussed the access condition on possession. One can understand the access condition non-normatively. Schroeder (2011), for example, understands it in terms of presentational mental states. If we are interested in understanding the possession of objective epistemic reasons, we will want to appeal to factive mental states. As noted in $\$ 3.3$, we could either (i) appeal to knowledge and argue that it is non-normative and prior to justification or (ii) argue that factive mental states like seeing that $\mathrm{p}$ are not species of knowledge and are non-normative.

\subsection{Another Sufficiency Objection}

The Fundamentality Objection amounts to a Sufficiency Objection. But Turri (2010) raises a different Sufficiency Objection. He argues that believing for sufficient epistemic reasons is insufficient for doxastic justification, and concludes that there is a normative dimension to doxastic justification that reasons don't illuminate.

\footnotetext{
${ }^{28}$ Schroeder (2011) traces this view to Feldman (1988: 90), who says there "is a good reason to include an epistemic acceptability constraint on evidence possessed." But this is a questionable interpretation, since Conee and Feldman are non-doxastic mentalists, and think evidence grounds justification.

${ }^{29}$ See Beddor (2015)
} 
Consider one of Turri's examples. ${ }^{30}$ Proper and Improper are jurors at Mansour's trial. They have massive evidence - call it E-that Mansour is guilty. Both conclude he is guilty. But while Proper derives the conclusion via inference to the best explanation, Improper uses a ridiculous inference rule to derive the conclusion from E. Improper's belief is not doxastically justified. Still, Turri insists, Improper does believe for a sufficient reason (viz., E).

One might conclude that something more is needed for justified belief than belief for sufficient reasons. What else? One answer is inferential competence. ${ }^{31}$ If it is a normative property distinct from reasons, one might conclude that we need some normativity that goes beyond reasons to understand doxastic justification. Indeed, Turri argues that we should take doxastic justification to be more fundamental than the propositional justification generated by reasons.

There are many ways to respond to this Sufficiency Objection. One way is to insist that in a clear sense, Miss Improper does not believe for a sufficient normative reason. ${ }^{32}$ Another way is to agree that something else is necessary for doxastic justification but to claim that it isn't normative; process reliabilists like Goldman (2012:7) use the same cases to defend this moral. A third way is to agree that something else normative is necessary but to insist that it is analyzable in terms of reasons: inferential competence is just a reliable ability to heed normative reasons.

\section{Conclusion}

The literature on normative epistemic reasons is young. The issues discussed above remain live and unresolved. But we have encountered themes of which there should be increasing recognition. Firstly, it is highly controversial to identify normative epistemic reasons with mental states. Secondly, giving an adequate characterization of what makes a reason epistemic is trickier than one might have imagined: evidentialism is not clearly viable. Thirdly, reflection on the distinction between subjective and objective reasons raises difficulties for any attempt to analyze all epistemic statuses in terms of reasons. But, finally, some doubts about "reasons first" epistemology overlook distinctions to which the broader literature on reasons should make us better attuned.

\section{References}

Alston, W. 1988. “An Internalist Externalism.” Synthese 74: 265-283.

Armstrong, D. 1973. Belief, Truth and Knowledge. Cambridge: Cambridge University Press.

Austin, J. L. 1962. Sense and Sensibilia. Oxford: Oxford University Press.

Beddor, R. 2015. "Evidentialism, Circularity, and Grounding." Philosophical Studies 172: 1847-1868.

Broome, J. 2013. Rationality through Reasoning. Oxford: Blackwell.

Brueckner, A. 2009. "E=K and Perceptual Knowledge" in Greenough, P. and Pritchard, D. (eds.) Williamson on Knowledge. Oxford: Oxford University Press.

Conee, E. and Feldman, R. 2004. Evidentialism. Oxford: Oxford University Press.

Conee, E. and Feldman, R. 2008. "Evidence" in Smith, Q. (ed.) Epistemology: New Essays. Oxford: Oxford University Press.

Dancy, J. 2000. Practical Reality. Oxford: Oxford University Press.

Davidson, D. 1980. Essays on Actions and Events. Oxford: Clarendon Press.

Davidson, D. 1986. "A Coherence Theory of Truth and Knowledge" in Lepore, E. (ed.) Truth and Interpretation. New York: Blackwell.

Dretske, F. 1981. Knowledge and the Flow of Information. Cambridge MA: The MIT Press.

Fantl, J. and McGrath, M. 2002. "Evidence, Pragmatics, and Justification." Philosophical Review 111: 67-94.

Fantl, J. and McGrath, M. 2009. Knowledge in an Uncertain World. Oxford: Oxford University Press. Feldman, R. 1988. "Having Evidence" in Austin, D. Philosophical Analysis. Dordrecht: Kluwer Academic Publishers.

Foley, R. 1987. The Theory of Epistemic Rationality. Cambridge, MA: Harvard University Press.

\footnotetext{
${ }^{30}$ See Turri (2010: 315-6)

${ }^{31}$ Cf. Millar (1991: 57).

${ }^{32}$ See Lord and Sylvan (Ms).
} 
Foley, R. 2004. "A Trial Separation between the Theory of Knowledge and the Theory of Justified Belief." in Greco, J. (ed.) Ernest Sosa and His Critics. Oxford: Blackwell.

Gardner, J. 2007. Offences and Defences. Oxford: Oxford University Press.

Ginsborg, H. 2006. "Reasons for Belief." Philosophy and Phenomenological Research 72: 286-318.

Goldman, A. 1967. "A Causal Theory of Knowing." Journal of Philosophy 73: 771-91.

Goldman, A. 2012. Reliabilism and Contemporary Epistemology. Oxford: Oxford University Press.

Hieronymi, P. 2005. "The Wrong Kind of Reason.” Journal of Philosophy 102: 437-457.

Hieronymi, P. 2013. "The Use of Reasons in Thought (and the Use of Earmarks in Arguments)." Ethics 124: 114-127.

Huemer, M. 2001. "Skepticism and the Veil of Perception." Lanham: Rowman \&Littlefield.

Jenkins, C. 2007. "Entitlement and Rationality." Synthese 157: 25-45.

Kolodny, N. 2007. "How Does Coherence Matter?" Proceedings of the Aristotelian Society 107: 229263.

Kornblith, H. 2008. "Knowledge Needs No Justification" in Smith, Q. (ed.) Epistemology: New Essays. Oxford: Oxford University Press.

Kornblith, H. 2015. "The Role of Reasons in Epistemology." Episteme 12: 225-239.

Littlejohn, C. 2012. Justification and the Truth Connection. Cambridge: Cambridge University Press.

Littlejohn, C. Forthcoming. "A Plea for Epistemic Excuses" in Dorsch, F. and Dutant, J. (eds.) The New Evil Demon Problem. Oxford: Oxford University Press.

Lord, E. 2010. "Having Reasons and the Factoring Account." Philosophical Studies 149: 283-96.

Lord, E. 2013. The Importance of Being Rational. Ph.D. Thesis, Princeton University.

Lord, E. 2014. "The Coherent and the Rational." Analytic Philosophy 54: 151-175.

Lord, E. and Sylvan, K. Ms. "Prime Time (for the Basing Relation)"

Lyons, J. 2009. Perception and Basic Beliefs. Oxford: Oxford University Press.

Mantel, S. 2015. "Worldly Reasons: An Ontological Inquiry into Motivating Considerations and Normative Reasons." Pacific Philosophical Quarterly. Online first. DOI: 10.1111/papq.12094

McDowell, J. 1995. "Knowledge and the Internal." Philosophy and Phenomenological Research 55: $877-93$.

Millar, A. 1991. Reasons and Experience. Oxford: Clarendon Press.

Millar, A. 2014. "Reasons for Belief, Perception, and Reflective Knowledge." Proceedings of the Aristotelian Society Supplementary Volume 88: 1-19.

McGrath, M. Forthcoming. "Looks and Perceptual Justification." Philosophy and Phenomenological Research.

Owens, D. 2000. Reason without Freedom. London: Routledge.

Parfit, D. 2001. "Rationality and Reasons" in Dan Egonsson, Bjorn Petterson and Toni RonnowRasmussen (eds.) Exploring Practical Philosophy. Aldershot: Ashgate.

Parfit, D. 2011. On What Matters. Oxford: Oxford University Press.

Pollock, J. 1974. Knowledge and Justification. Princeton: Princeton University Press.

Pollock, J. and Cruz, J. 1999. Contemporary Theories of Knowledge, Second Edition. Lanham: Rowman \& Littlefield.

Pryor, J. 2000. "The Skeptic and the Dogmatist." Noûs 34: 517-549.

Reisner, A. 2012. "Is There Reason to Be Theoretically Rational?" in Reisner, A. and Steglich-Petersen,

A. (eds.) Reasons for Belief. Cambridge: Cambridge University Press.

Schroeder, M. 2007. Slaves of the Passions. Oxford: Oxford University Press.

Schroeder, M. 2008. "Having Reasons." Philosophical Studies 139: 57-71.

Schroeder, M. 2010. "Value and the Right Kind of Reason." Oxford Studies in Metaethics 5: 25-55.

Schroeder, M. 2011. "What Does It Take to 'Have' a Reason?" in Reisner, A. and Steglich-Petersen, A. (eds.) Reasons for Belief. Cambridge: Cambridge University Press.

Schroeder, M. 2012. "Stakes, Withholding, and Pragmatic Encroachment on Knowledge." Philosophical Studies 160.2: 265-285.

Schroeder, M. 2015a. “Is Knowledge Normative?” Philosophical Issues 25: 379-395.

Schroeder, M. 2015b. "Knowledge Is Belief for Sufficient (Subjective and Objective) Reason." Oxford Studies in Epistemology 5: 226-252.

Sosa, E. 2007. Apt Belief and Reflective Knowledge, Volume 1. Oxford: Oxford University Press.

Sosa, E. 2015. Judgment and Agency. Oxford: Oxford University Press. 
Sylvan, K. 2014. "Reasons in Epistemology." Oxford Bibliographies Online.

Sylvan, K. 2015. "What Apparent Reasons Appear to Be." Philosophical Studies 172(3): 587-606 (2015).

Sylvan, K. Ms-1. "Knowledge as a Non-Normative Relation."

Sylvan, K. Ms-2. "On Divorcing the Rational and the Justified."

Sylvan, K and Sosa, E. Forthcoming. "The Place of Reasons in Epistemology" in Star, D. (ed.) The Oxford Handbook of Reasons and Normativity. Oxford: Oxford University Press.

Turri, J. 2009. "The Ontology of Epistemic Reasons." Nous 43: 490-512.

Turri, J. 2010. "On the Relationship between Propositional and Doxastic Justification." Philosophy and Phenomenological Research 80.2: 312-26.

Williamson, T. 2000. Knowledge and its Limits. Oxford: Oxford University Press.

Wright, C. 2004. "Warrant for Nothing (and Foundations for Free)?" Aristotelian Society Supplementary Volume 78: 167-212. 